\title{
Sintering Behavior, Microstructure, and Mechanical Properties: A Comparison among Pressureless Sintered Ultra-Refractory Carbides
}

\author{
Laura Silvestroni and Diletta Sciti \\ CNR-ISTEC, Institute of Science and Technology for Ceramics, Via Granarolo 64, I-48018 Faenza, Italy \\ Correspondence should be addressed to Laura Silvestroni, laura.silvestroni@istec.cnr.it \\ Received 12 July 2010; Accepted 10 October 2010 \\ Academic Editor: Paul Munroe
}

Copyright (C) 2010 L. Silvestroni and D. Sciti. This is an open access article distributed under the Creative Commons Attribution License, which permits unrestricted use, distribution, and reproduction in any medium, provided the original work is properly cited.

Nearly fully dense carbides of zirconium, hafnium, and tantalum were obtained by pressureless sintering at $1950{ }^{\circ} \mathrm{C}$ with the addition of 5-20 vol\% of $\mathrm{MoSi}_{2}$. Increasing the amount of sintering aid, the final density increased too, thanks to the formation of small amounts of liquid phase constituted by M-Mo-Si-O-C, where M is either $\mathrm{Zr}$, Hf, or Ta. The matrices of the composites obtained with the standard procedure showed faceted squared grains; when an ultrasonication step was introduced in the powder treatment, the grains were more rounded and no exaggerated grains growth occurred. Other secondary phases observed in the microstructure were $\mathrm{SiC}$ and mixed silicides of the transition metals. Among the three carbides prepared by pressurless sintering, TaC-based composites had the highest mechanical properties at room temperature (strength $590 \mathrm{MPa}$, Young's modulus $480 \mathrm{GPa}$, toughness 3.8 MPa $\mathrm{m}^{1 / 2}$ ). HfC-based materials showed the highest sinterability (in terms of final density versus amount of sintering aid) and the highest high-temperature strength $\left(300 \mathrm{MPa}\right.$ at $\left.1500{ }^{\circ} \mathrm{C}\right)$.

\section{Introduction}

The carbides of the group IV-VI transition metals have extremely high melting points $\left(3000-4000^{\circ} \mathrm{C}\right)$ and are commonly referred to as "refractory carbides". Beside their stability at high temperatures, these compounds possess extremely high hardness, thus finding industrial use in cutting tools and wear-resistant parts [1-3]. They also have good corrosion resistance, as they are attacked only by concentrated acid or base in the presence of oxidizing agents, and retain good corrosion resistance to high temperatures. The refractory carbides are stiff, with Young's modulus values competing with those of SiC. In addition, they have good thermal conductivity, permitting heat to be drawn away from the superheated surfaces. This gives them a benefit over other refractory materials, such as $\mathrm{AlN}, \mathrm{SiC}$, and $\mathrm{Si}_{3} \mathrm{~N}_{4}$, which do not conduct heat so well [1-3]. For high-temperature applications, they outperform the "superalloys" in such applications as rocket nozzles and jet engine parts, where ablation resistance at temperatures of $2500^{\circ} \mathrm{C}$ and above is crucial. The electrical resistivity of the carbides is only slightly higher than that of the host metals, reflecting the metallic behaviour of these compounds and their strong metal-to-metal bond [1-3]. One drawback of these carbides is their poor oxidation resistance, as reported in the literature [1-4].

Among this class of materials, Zirconium carbide has found industrial importance as coating for atomic-fuel particle for nuclear-fission power plants, owing to its low activation under neutron irradiation [1-3]. Hafnium carbide is, with tantalum carbide, the most refractory compound available [1-3]. Hafnium carbide is considered a candidate material for high-temperature solar absorbers, because of its melting point above $3300^{\circ} \mathrm{C}$ and its intrinsic spectral selectivity [1-3]. Hafnium and Zirconium carbides can also be considered for thermoionic/thermoelectric converters at high temperature, by proper tuning of the grain boundary phases or carrier concentration and mobility. Tantalum carbide is produced industrially in appreciable quantity with a world production estimated at 500 tons annually (1994) 
and is generally used in combination with WC-Co as cutting tools to improve thermal shock resistance, high-temperature hardness, cratering, and cutting characteristics [1-3].

In spite of their excellent properties, carbides have been hardly developed on an industrial scale due to the high cost of the raw materials and of processing and sintering. The high melting point makes them difficult to sinter unless temperatures higher than $2000-2300^{\circ} \mathrm{C}$ and mechanical pressure are applied. Thus, pure carbides have been sintered with pressure-assisted techniques, such as hot pressing, reactive hot pressing, and spark plasma sintering [5-15]. As a consequence of these extreme processing conditions, the final ceramics possess a coarse microstructure $(10-20 \mu \mathrm{m})$ with trapped porosity and poor mechanical properties $[6,7]$.

The purpose of this study is to develop carbide-based materials which can be consolidated by pressureless sintering at temperatures lower than $2000^{\circ} \mathrm{C}$. From the technological point of view, with this technique, complex-shaped components can be achieved at competitive costs of production. Moreover, by keeping the temperature below $2000^{\circ} \mathrm{C}$ it is hoped for the achievement of a fine and homogeneous microstructure which displays good mechanical properties. To this aim, the studied compositions have been added with $\mathrm{MoSi}_{2}$, as this intermetallic phase is known to improve the densification of other ultra-refractory ceramics such as $\mathrm{ZrB}_{2}$ and $\mathrm{HfB}_{2}$, thanks to the formation of liquid phases [16]. The microstructure and mechanical properties at room and high temperature are presented and compared.

\section{Experimental Procedure}

Commercial powders were used to prepare the ceramic materials; details are reported in Table 1.

Different compositions were prepared by varying the $\mathrm{MoSi}_{2}$ content between 5 and $20 \mathrm{vol} \%$ (Table 2). The powder mixtures were milled for $24 \mathrm{~h}$ in absolute ethanol using zirconia milling media, subsequently dried in a rotary evaporator and sieved through a $250 \mu \mathrm{m}$ screen. For selected compositions, an ultrasonication step was included in the experimental procedure. Four-centimeter diameter pellets were linearly pressed and subsequently cold isostatically pressed under a $350 \mathrm{MPa}$ pressure. The pellets were pressureless sintered in a resistance-heated graphite furnace under a flowing argon atmosphere $(\sim 1 \mathrm{~atm})$ at $1950^{\circ} \mathrm{C}$ for $60 \mathrm{~min}$. After sintering, the bulk densities were measured by Archimedes method.

The $1950^{\circ} \mathrm{C}$ sintered samples were examined using Xray diffraction (XRD, Siemens D500, Karlsruhe, Germany) to identify crystalline phases. X-ray diffraction was also performed on the starting carbides powders in order to assess the C:M stoichiometry, which resulted nearly 1 to 1 (Table 1). The microstructures were polished with diamond paste to $0.25 \mu \mathrm{m}$ and were analyzed by scanning electron microscopy (SEM, Cambridge S360, Cambridge, UK) and energy dispersive spectroscopy (EDS, INCA Energy 300, Oxford Instruments, High Wycombe, UK). The mean grain size of carbides was evaluated on micrographs of polished sections through the circle method. TEM samples were prepared by cutting $3 \mathrm{~mm}$ discs from the sintered pellets. These were mechanically ground down to about $20 \mu \mathrm{m}$ and then further ion beam thinned until small perforations were observed by optical microscopy. Local phase analysis was performed using transmission electron microscopy (TEM) equipped with an energy-dispersive X-ray system (FEI, CM12, Eindhoven, The Netherlands; EDS, EDAX Genesis 2000, Ametek GmbH; Wiesbaden, Germany) operating at a nominal voltage of $120 \mathrm{keV}$. High-resolution investigations were performed using an FEI CM20 STEM operating at a nominal voltage of $200 \mathrm{keV}$.

Vickers microhardness (HV) was measured on polished surfaces, with a load of $1 \mathrm{Kg}$, using a standard microhardness tester (Zwick 3212, Ulm, Germany). Eight indentations were carried out for each composition. Young's modulus (E) was measured by the resonance frequency method on $28 \times$ $8 \times 0.8 \mathrm{~mm}^{3}$ samples using an H\&P gain-phase analyzer (Hewlett Packard, Tokyo, Japan). The 4-pt flexural strength $(\sigma)$ was measured at room temperature, $1200^{\circ} \mathrm{C}$ and $1500^{\circ} \mathrm{C}$ on chamfered bars that were nominally $25 \times 2.5 \times 2 \mathrm{~mm}^{3}$, using a crosshead speed of $0.5 \mathrm{~mm} / \mathrm{min}$ on a universal screwtype testing machine (Instron 6025, High Wycombe, UK). The high-temperature tests were carried out under a flowing argon protective gas. Before the bending test, a soaking time of 18 minutes was set to reach thermal equilibrium. For each sample, 5 specimens were tested at room temperature and 3 specimens for each high-temperature point. On the same testing machine, fracture toughness $\left(\mathrm{K}_{\mathrm{Ic}}\right)$ was evaluated using the chevron-notched beam (CNB) technique on $25 \times$ $2 \times 2.5 \mathrm{~mm}^{3}$ bars. The test bars, were notched with a $0.1 \mathrm{~mm}$ thick diamond saw; the chevron-notch tip depth and average side length were about 0.12 and 0.80 of the bar thickness, respectively. The "slice model" equation of Munz et al. [17] was used for the calculation of $\mathrm{K}_{\mathrm{Ic}}$. At least three specimens were tested for each composition.

\section{Results and Discussion}

\subsection{Sintering Behavior}

3.1.1. $\mathrm{ZrC}$-Based Materials. A pressureless sintering test on pure $\mathrm{ZrC}$ was performed at $1950^{\circ} \mathrm{C}$ for 60 minutes of holding time, but the final density reached only $\sim 73 \%$ of the theoretical value, as reported in Table 2. An image of the monolithic material is given in Figure 1(a) showing that necks formation is at a very early stage and that the dominant feature is open porosity. Sintering cycles of the $\mathrm{MoSi}_{2}$-doped materials were carried out in the temperature range $1850-1970^{\circ} \mathrm{C}$. The increase of either the sintering temperature or the amount of $\mathrm{MoSi}_{2}$ generally led to an improvement of the final relative density. For $\mathrm{ZrC}-20 \mathrm{vol} \%$ $\mathrm{MoSi}_{2}$ sample (ZCM20), a relative density of $96.8 \%$ was obtained at $1950^{\circ} \mathrm{C}$.

3.1.2. HfC-Based Materials. As expected, monolithic HfC showed poor densification, achieving a final relative density of about $70 \%$ and a mean grain size in the range of 
TABLE 1: Characteristics of the starting powders and lattice parameter "a" calculated by x-ray diffraction.

\begin{tabular}{|c|c|c|c|c|c|c|c|c|c|c|}
\hline Powder & $\begin{array}{l}\text { Crystal } \\
\text { structure }\end{array}$ & Supplier & M. g. s. $(\mu \mathrm{m})$ & $\begin{array}{l}\text { Particle } \\
\text { size range } \\
(\mu \mathrm{m})\end{array}$ & $\begin{array}{c}\text { BET } \\
\left(\mathrm{m}^{2} / \mathrm{g}\right)\end{array}$ & $\begin{array}{l}\text { Purity } \\
(\%)\end{array}$ & $\begin{array}{l}\text { Impurities } \\
(\mathrm{wt} \%)\end{array}$ & $\begin{array}{l}\mathrm{C} / \mathrm{M} \\
\text { ratio }\end{array}$ & $\begin{array}{l}\text { "a" from } \\
\text { PDFC } \\
\AA\end{array}$ & $\begin{array}{c}\text { "a” from } \\
\text { XRD } \\
\AA\end{array}$ \\
\hline $\mathrm{MoSi}_{2}$ & Tetragonal & $\begin{array}{l}\text { Aldrich, } \\
\text { Milwaukee, } \\
\text { USA }\end{array}$ & 2.8 & $0.3-5.0$ & 1.6 & $>99$ & $O: 1$ & - & - & - \\
\hline $\mathrm{ZrC}$ & Cubic & $\begin{array}{l}\text { Grade B, } \\
\text { H.C. Starck, } \\
\text { Karlsruhe, } \\
\text { Germany }\end{array}$ & 3.8 & $0.8-8.0$ & - & $>99$ & $\begin{array}{c}\mathrm{C}_{\text {free }}: 1.5 \\
\mathrm{O}: 0.6 \\
\mathrm{~N}: 0.8 \\
\text { Fe }: 0.05 \\
\text { Hf: } 2\end{array}$ & $\begin{array}{c}0.78 \\
(\min )\end{array}$ & $\begin{array}{c}4.692 \\
\# 65-0973\end{array}$ & 4.698 \\
\hline $\mathrm{HfC}$ & Cubic & $\begin{array}{l}\text { Cerac Inc., } \\
\text { Milwaukee, } \\
\text { WI, USA }\end{array}$ & 1.41 & $0.2-1.5$ & 1.19 & 99.5 & $\begin{array}{l}\mathrm{U}: 0.0002 \\
\mathrm{Zr}:<0.6\end{array}$ & 0.92 & $\begin{array}{c}4.637 \\
\# 65-0975\end{array}$ & 4.641 \\
\hline $\mathrm{TaC}$ & Cubic & $\begin{array}{l}\text { Cerac Inc., } \\
\text { Milwaukee, } \\
\text { WI, USA }\end{array}$ & 1.21 & $0.2-1.5$ & 0.78 & 99.5 & $\begin{array}{c}\mathrm{Ca}: 0.01 \\
\mathrm{Cd}< \\
0.0007 \\
\mathrm{Cr}< \\
0.0005 \\
\mathrm{Fe}: 0.02 \\
\mathrm{Na}: 0.03 \\
\mathrm{Nb}: 0.03 \\
\mathrm{Ti}: 0.04\end{array}$ & 0.98 & $\begin{array}{c}4.460 \\
\# 65-0282\end{array}$ & 4.461 \\
\hline
\end{tabular}

TABle 2: Densification data for the samples pressureless sintered at $1950^{\circ} \mathrm{C} / 60 \mathrm{~min}$ in flowing Ar; Mean grain size of the matrix and mechanical properties of the composites: hardness (HV1.0), Young's modulus (E), fracture toughness ( $\mathrm{K}_{I c}$ ) by CNB method, and 4-pt flexural strength $(\sigma)$ at room and high temperature.

\begin{tabular}{|c|c|c|c|c|c|c|c|c|c|c|c|c|}
\hline Label & $\begin{array}{c}\text { Composition } \\
\text { Vol } \%\end{array}$ & $\begin{array}{c}\text { Green } \\
\text { Density } \\
\% \\
\end{array}$ & $\begin{array}{c}\text { Exp. } \\
\text { Density } \\
\mathrm{g} / \mathrm{cm}^{3}\end{array}$ & $\begin{array}{c}\text { Th. } \\
\text { Density } \\
\mathrm{g} / \mathrm{cm}^{3}\end{array}$ & $\begin{array}{c}\text { Relative } \\
\text { density } \\
\%\end{array}$ & $\begin{array}{l}\text { M.g.s. } \\
\mu \mathrm{m}\end{array}$ & $\begin{array}{c}\mathrm{HV} 1.0 \\
\mathrm{GPa}\end{array}$ & $\begin{array}{c}\mathrm{E} \\
\mathrm{GPa}\end{array}$ & $\begin{array}{c}\mathrm{K}_{I c} \\
\mathrm{MPa} \cdot \mathrm{m}^{1 / 2}\end{array}$ & $\begin{array}{c}\sigma_{R T} \\
\mathrm{MPa}\end{array}$ & $\begin{array}{c}\sigma 1200^{\circ} \mathrm{C} \\
\mathrm{MPa}\end{array}$ & $\begin{array}{c}\sigma 1500^{\circ} \mathrm{C} \\
\mathrm{MPa}\end{array}$ \\
\hline $\mathrm{ZC0}$ & $100 \mathrm{ZrC}$ & 63.9 & 4.81 & 6.63 & $\sim 73$ & 3 & - & - & - & - & - & - \\
\hline ZC5 & $95 \mathrm{ZrC}+5 \mathrm{MoSi}_{2}$ & 66.4 & 5.52 & 6.62 & 83.4 & - & - & - & - & - & - & 一 \\
\hline $\mathrm{ZC} 10$ & $90 \mathrm{ZrC}+10 \mathrm{MoSi}_{2}$ & 63.4 & 6.11 & 6.60 & 92.7 & - & - & - & - & - & - & - \\
\hline $\mathrm{ZC} 20$ & $80 \mathrm{ZrC}+20 \mathrm{MoSi}_{2}$ & 65.2 & 6.36 & 6.57 & 96.8 & 6 & $12.7 \pm 1.0$ & $346 \pm 4$ & $3.5 \pm 0.2$ & $272 \pm 12$ & $156 \pm 6$ & - \\
\hline $\mathrm{HC}$ & $100 \mathrm{HfC}$ & 57.1 & 8.78 & 12.69 & $\sim 70$ & 1.5 & - & - & - & - & - & - \\
\hline HC5 & $95 \mathrm{HfC}+5 \mathrm{MoSi}_{2}$ & 55.8 & 12.13 & 12.37 & 98.1 & 4 & $15.6 \pm 0.6$ & $434 \pm 4$ & $3.62 \pm 0.13$ & $465 \pm 45$ & $408 \pm 31$ & $241 \pm 112$ \\
\hline $\mathrm{HC} 10$ & $90 \mathrm{HfC}+10 \mathrm{MoSi}_{2}$ & 55.6 & 11.79 & 12.05 & 97.8 & 3 & $16.1 \pm 0.4$ & $415 \pm 4$ & $3.53 \pm 0.29$ & $452 \pm 90$ & $357 \pm 21$ & $306 \pm 18$ \\
\hline $\mathrm{HC} 10 *$ & $90 \mathrm{HfC}+10 \mathrm{MoSi}_{2}$ & 56.5 & 11.94 & 12.05 & 99.1 & 2 & $16.5 \pm 0.5$ & - & - & $538 \pm 22$ & - & - \\
\hline $\mathrm{HC} 20$ & $80 \mathrm{HfC}+20 \mathrm{MoSi}_{2}$ & 55.2 & 11.01 & 11.41 & 96.5 & 3 & $15.5 \pm 0.9$ & $385 \pm 4$ & $3.43 \pm 0.34$ & $383 \pm 74$ & $350 \pm 78$ & $299 \pm 71$ \\
\hline TC0 & $100 \mathrm{TaCC}$ & 57.1 & 13.25 & 14.50 & $\sim 91$ & 6 & & & & & & \\
\hline TC5 & $95 \mathrm{TaC}+5 \mathrm{MoSi}_{2}$ & 58.5 & 13.09 & 14.09 & 92.9 & 6 & & & & & & \\
\hline TC10 & $90 \mathrm{TaC}+10 \mathrm{MoSi}_{2}$ & 58.2 & 13.45 & 13.67 & 98.4 & 5 & $12.5 \pm 0.8$ & & & & & \\
\hline TC20 & $80 \mathrm{TaC}+20 \mathrm{MoSi}_{2}$ & 56.6 & 12.32 & 12.86 & 95.8 & 7 & $12.1 \pm 0.7$ & $476 \pm 4$ & $3.83 \pm 0.14$ & $591 \pm 61$ & - & - \\
\hline
\end{tabular}

*After powders ultrasonication.

$1-2 \mu \mathrm{m}$ at $1950^{\circ} \mathrm{C}$ (Figure $1(\mathrm{~b})$ ). In contrast, the $\mathrm{MoSi}_{2}$ doped compositions showed an improved sinterability, with final densities in the range of $96-98 \%$ of the theoretical values, which were calculated with the rule of mixture on the basis of the starting compositions. Even in case of low addition of $\mathrm{MoSi}_{2}$, that is $5 \mathrm{vol} \%$, the final density was around 98\% (Table 1).
3.1.3. TaC-Based Materials. Monolithic $\mathrm{TaC}$ was sintered at $1950^{\circ} \mathrm{C}$ achieving a final relative density of about $91 \%$ and a mean grain size of about $6 \mu \mathrm{m}$ (Figure 1(c)). The addition of 5 to $20 \mathrm{vol} \%$ of $\mathrm{MoSi}_{2}$ enabled the achievement of a final density from 93 to $96 \%$ (Table 1).

For all the compositions, it is presumed that the final real density is higher than the value calculated on the basis 


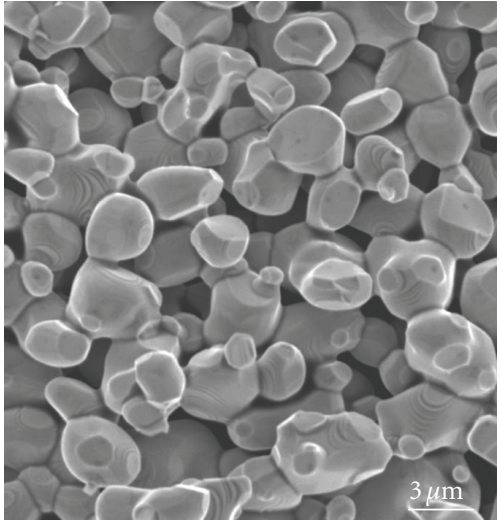

(a)

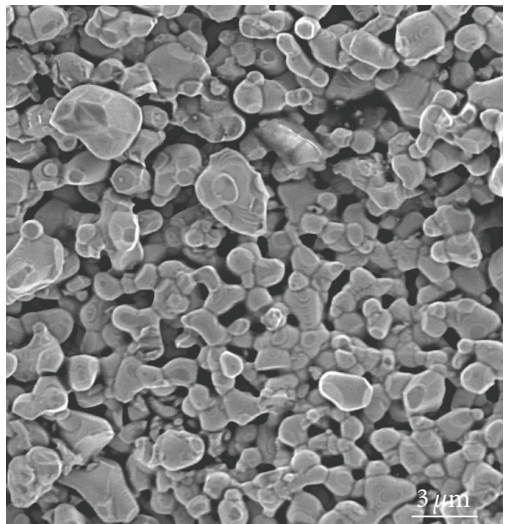

(b)

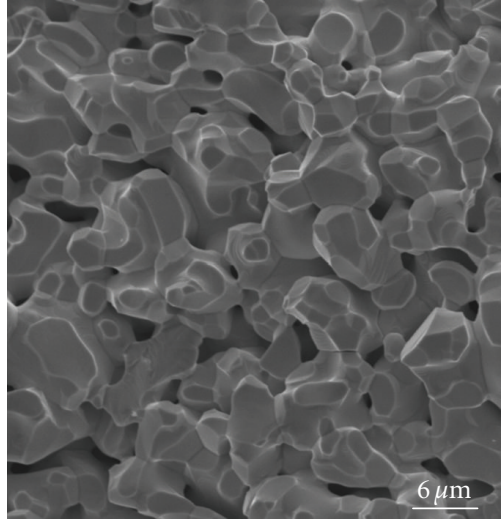

(c)

FIgURe 1: Fracture surfaces for monolithic (a) $\mathrm{ZrC}$, (b) $\mathrm{HfC}$ and (c) $\mathrm{TaC}$ showing a high level of residual porosity.

of the nominal composition, as in the final microstructure additional lower-density Si-based phases were observed, as explained in the next pharagraph.

\subsection{Microstructural Features}

3.2.1. $\mathrm{ZrC}-\mathrm{MoSi}_{2}$ Composites. According to the $\mathrm{X}$-ray diffraction pattern of the ZC20 sample, besides the reflections from cubic $\mathrm{ZrC}$ and tetragonal $\mathrm{MoSi}_{2}$, traces of $\beta$-silicon carbide were detected (Figure 2). Considering the wide range of stability of fcc transition metals carbides $\mathrm{MC}_{\mathrm{x}}$, X-ray diffraction at high angles was performed with a $\mathrm{Si}$ standard in order to detect any peaks shift. $\mathrm{MoSi}_{2}$ and $\mathrm{Si}$ peaks were in their theoretical position. On the contrary, the lattice parameter obtained for $\mathrm{ZrC}$ was $4.671 \AA$, significantly smaller than those reported on the PDF card 65-0973, $4.692 \AA$, indicating a shrinkage of the original cell. The shift of ZrC-peaks may indicate a decrease of the $\mathrm{MC}_{\mathrm{x}}$ stoichiometry [18] or the substitution of Mo atoms in $\mathrm{Zr}$ sites. The most plausible hypothesis seems to be the latter one for two reasons. (1) Carbon escape from $\mathrm{ZrC}$ lattice is improbable due to presence of free carbon in the raw powder (1.5 wt\%) and the C/CO-rich sintering environment. (2) The substitution of Mo atoms in $\mathrm{Zr}$ sites is possible as $\mathrm{Mo}$ and $\mathrm{Zr}$ have close atomic radii, 0.136 and $0.160 \mathrm{~nm}$, respectively.

In the back-scattered electron image of the polished section, Figure 3(a), small pores are recognizable as rounded black contrasting areas. Zirconium carbide grains have a squared shape and a mean grain size of $6.0 \mu \mathrm{m}$ (see Table 2); considering the starting powder mean grain size $(3 \mu \mathrm{m})$, it can be concluded that a fair grain coarsening occurred during sintering, probably due to the higher specific surface of the powder compared to the other two carbides. In Figure 3(a), MoSi $i_{2}$ is the grey phase with irregular shape, arranged among the matrix particles. The morphology of these regions suggests a liquid phase behavior during sintering, which favored the formation of high-density materials. By image analysis the presence of about $1 \%$ of $\mathrm{SiC}$ was confirmed. SiC appeared as dark irregular agglomerates of particles formed inside the $\mathrm{MoSi}_{2}$ phase. On the fractured surface it was noticed that the formation of $\mathrm{SiC}$ was more concentrated on the surface and gradually decreased towards the bulk (Figure 3(b)). Zr-Si phases with different stoichiometry were also detected in the microstructure; these phases were as large as several micrometers, contained traces of oxygen and Mo and were estimated to be around 34 vol\%. Zirconium silicide with stoichiometry close to $\mathrm{ZrSi}$ was found at the interface between $\mathrm{MoSi}_{2}$ and SiC. The very low dihedral angles and the wetted grain boundaries in Figures 3(c) and 3(d) suggest that these Si-based phases were liquid at the sintering temperature. A silicide with stoichiometry close to $\mathrm{ZrSi}_{2}$ was instead observed to form in contact with $\mathrm{MoSi}_{2}$, or at the interface between $\mathrm{ZrC}$ grains and $\mathrm{SiC}$ platelet, as shown in the TEM image of Figure 3(e). A defective substructure consisting in dislocations networks is clearly visible in the $\mathrm{ZrC}$ grains (Figure 3(e)). In $\mathrm{MoSi}_{2}$ grains, the formation of nanoprecipitates was observed to give rise to necklaces of dislocations; see Figure 4.

\subsubsection{HfC-MoSi $i_{2}$ Composites. XRD patterns of the dense} materials (not shown) revealed the presence of the starting $\mathrm{HfC}$ and $\mathrm{MoSi}_{2}$ phases. Each peak was exactly at the 2-theta angles predicted by PDF-cards.

The fracture surfaces showed mainly intergranular fracture for compositions HC5 and $\mathrm{HC} 10$ and partially transgranular fracture for composition HC20. The polished surfaces (Figure 5(a)) revealed HfC grains dispersed in the $\mathrm{MoSi}_{2}$ phase, which filled the space left by the HfC grains. It was noticed that $\mathrm{HfC}$ grains retained a rounded shape and reduced size in areas where the $\mathrm{MoSi}_{2}$ phase was more abundant. In contrast, large faceted $\mathrm{HfC}$ grains grew in areas where the $\mathrm{MoSi}_{2}$ phase was scarce, a feature which was particularly evident in composition HC20. Among the faceted grains, mixed products, around $50-100 \mathrm{~nm}$ wide, were detected by EDS analysis (Figure 6), containing Hf, Si, Mo, C, and oxygen. The amount of this phase was calculated to be below 1 vol\% by image analysis. The formation of this intermediate phase indicates the possibility of mutual solubility between the starting compounds. Furthermore, this suggests that sintering was aided by an Mo-Si-based 


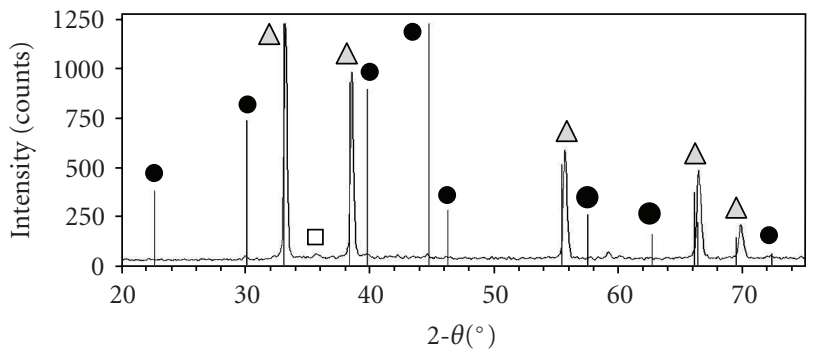

$\triangle \mathrm{ZrC} \# 65-0973$

- $\mathrm{MoSi}_{2} \# 65-2645$

$\mathrm{SiC} \# 49-1428$

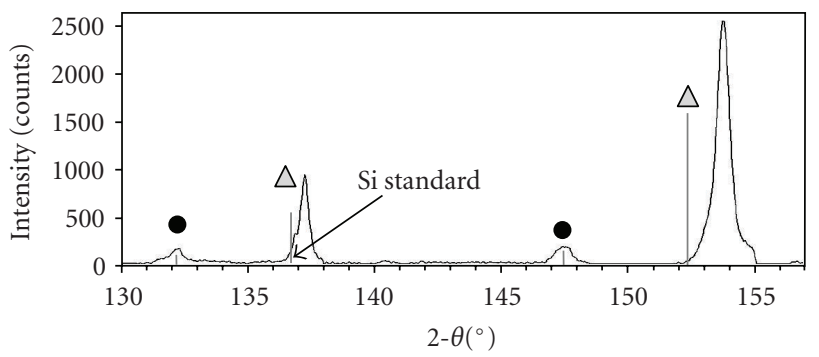

$\triangle \mathrm{ZrC} \# 65-0973$

- $\mathrm{MoSi}_{2} \# 65-2645$

$\square \mathrm{SiC} \# 49-1428$

(a)

(b)

Figure 2: Comparison between experimental reflections and theoretical lines from PDF cards. The x-ray diffraction was performed at (a) low 2-theta angles and (b) high 2-theta angles. Note in b) the signal of the Si-standard.

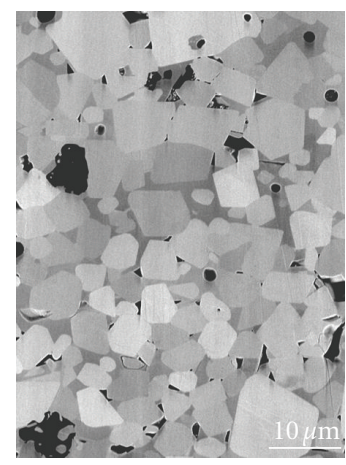

(a)

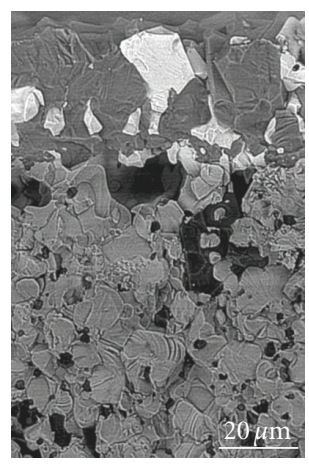

(b)

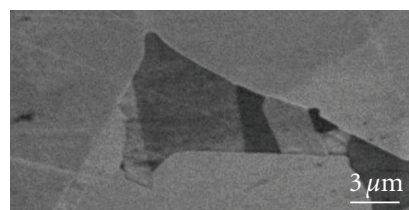

(c)

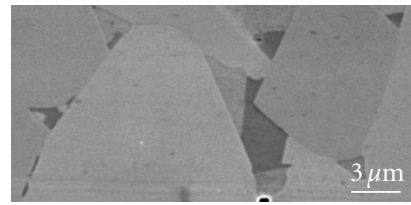

(d)

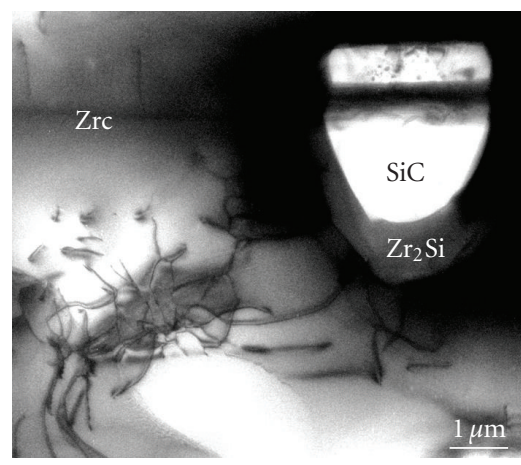

(e)

FIGURE 3: (a) SEM micrographs of the polished surface of ZC20; the bright phase is ZrC, the grey phase is MoSi ${ }_{2}$, the dark irregular particles are $\mathrm{SiC}$, whilst the little rounded dark ones are residual porosity. (b) BSE-SEM image of the fracture surface showing a $15 \mu \mathrm{m}$-thick SiC layer on the edge of ZC20. (c) Zr-Si phases at the interface $\mathrm{ZrC}-\mathrm{MoSi}_{2}$. Darker regions correspond to Si-richer $\mathrm{Zr}_{x} \mathrm{Si}_{y}$ phases. (d) Wetted grain boundaries and Zr-Si phases with different stoichiometry indicating local crystallization from liquid phase. (e) BF-TEM image of ZC20 composite showing the formation of $\mathrm{SiC}$ on $\mathrm{Zr}_{2} \mathrm{Si}$ phase.

liquid phase, acting as medium for matter transport by diffusion between nearest neighbor grains and hence favoring grain coarsening. This hypothesis is consistent with the observation that coarser HfC grains were developed in regions where they were in close proximity, with grain coarsening being aided by shorter diffusion distances.

After sintering the mean grain size of the composites increased from 1.4 to about $3-4 \mu \mathrm{m}$ (Table 2), with some additional larger grains up to $20 \mu \mathrm{m}$ in size. When the ultrasonication step was included in the experimental procedure, the mean grain size decreased to about $2 \mu \mathrm{m}$, grains were more homogeneous in size and shape, and abnormal grain growth was suppressed. An example of the microstructure without and with ultrasonication stage can be observed in Figures 5(a) and 5(b). The beneficial effect of powder ultrasonication relies on the disagglomeration of the fine starting powder, thus hindering the particles coalescence at high temperature.

3.2.3. TaC-MoSi $i_{2}$ Composites. The crystalline phases identified by X-ray diffraction (Figure 7) were cubic $\mathrm{TaC}$ and tetragonal $\mathrm{MoSi}_{2}$. No other secondary phases were detected both at low and high 2-Theta angles. As it can be observed in the spectrum, $\mathrm{MoSi}_{2}$ peaks fall in the position predicted by the PDF-card; on the contrary, $\mathrm{TaC}$ peaks are shifted at higher angles, indicating a possible substitution of Mo into Ta sites or carbon loss [19], analogously to ZrC-system. From X-ray data it was found that $\mathrm{TaC}$ lattice parameter changed from $4.461 \AA$ in the starting powder to $4.451 \AA$ in the composite. However, a significant carbon loss should be ruled out, because the composite after sintering retained a golden color which generally indicates a $\mathrm{C} / \mathrm{M}$ ratio very close to 1 [20].

The fracture surface of the composites containing $\mathrm{MoSi}_{2}$ proceeded intergranularly. The material containing $5 \mathrm{vol} \%$ of sintering aid showed about $10 \%$ of residual porosity, confirming Archimedes' density measurements, whilst those containing 10 and $20 \%$ were fully dense (Figure $8(a)$ ), despite the low relative densities reported in Table 2. Increasing the amount of $\mathrm{MoSi}_{2}$, a higher amount of $\mathrm{SiC}$ and $\mathrm{SiO}_{2}$ formed during sintering. Considering the bulk density of $\mathrm{TaC}, 14.5 \mathrm{~g} / \mathrm{cm}^{3}$, it is apparent that the presence of low 


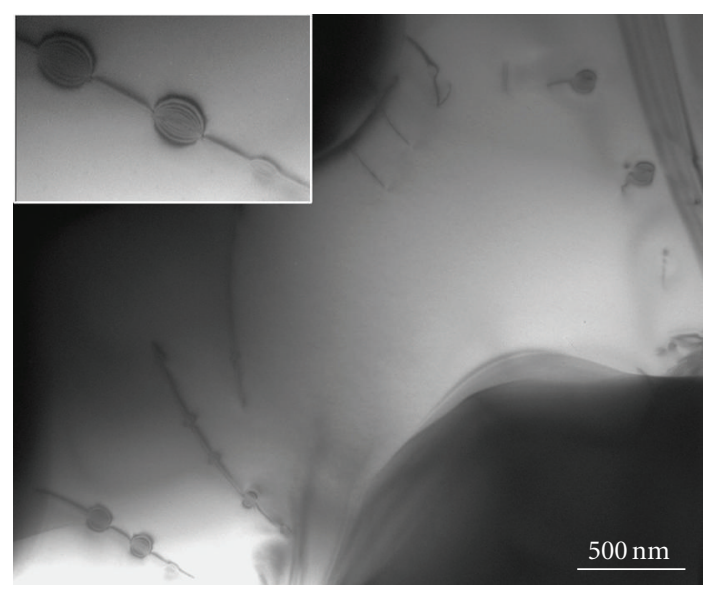

FIGURE 4: BF-TEM micrograph of an $\mathrm{MoSi}_{2}$ grains where necklaces of dilocations are visible (enlarged view in the inset).

amounts of $\mathrm{SiC}\left(3.2 \mathrm{~g} / \mathrm{cm}^{3}\right)$ and amorphous silica $\left(\sim 2 \mathrm{~g} / \mathrm{cm}^{3}\right)$ strongly decreases the final density. The matrix grains in the polished surface (Figure 8(b)) had a squared shape and were quite homogeneous in size, around $5 \mu \mathrm{m} . \mathrm{MoSi}_{2}$ appeared in the typical look as the previous materials, with irregular shape and very low dihedral angles, indicating its ductile behavior at the sintering temperature. In the apical part of $\mathrm{MoSi}_{2}$, at the interface with the matrix, a mixed phase was observed with composition close to $(\mathrm{Mo}, \mathrm{Ta})_{5} \mathrm{Si}_{3}$ (Figure 8(c)). In addition, silicides with stoichiometry $5: 3$ containing carbon traces were observed at the triple points with nonwetting tendency, as shown in Figure 8(d). These secondary phases were estimated to be around 2 vol\%.

3.3. Mechanical Properties. The properties of the composites are summarized in Table 2. Due to the high level of porosity, the mechanical characterization of monolithic carbides was not carried out.

The hardness was $13 \mathrm{GPa}$ for $\mathrm{ZC} 20$, in the range of 14$16 \mathrm{GPa}$ for HC5-20 composites, and 12 for TC20. These values are substantially lower than the values reported in the available database for monolithic carbides $(\mathrm{ZrC} \sim 27$ GPa, HfC $\sim 26 \mathrm{GPa}, \mathrm{TaC} \sim 18 \mathrm{GPa}$ ) [21]. This property was certainly affected by the presence of softer secondary phases, as $\mathrm{MoSi}_{2}$ (9-11 GPa) [22] and M-silicides, as well as by residual porosity and the relatively coarse microstructure, especially in the $\mathrm{ZrC}$-based material.

Young's modulus for ZC20 was $346 \mathrm{GPa}$, slightly below the $400 \mathrm{GPa}$ reported for the monolithic material [23]. The reasons for this low value find origins in a discrete amount of porosity and presence of secondary phases, such as $\mathrm{Zr}_{x} \mathrm{Si}_{y}$ which are expected to be softer $(\mathrm{E} \sim 200 \mathrm{GPa})$. In the case of HfC-based ceramics, Young's modulus showed an almost linear decrease with increasing $\mathrm{MoSi}_{2}$ content. Just to give an indication of the goodness of these pressureless materials, a value of about $380 \mathrm{GPa}$ has been reported in literature for a hot pressed HfC monolithic material, containing a residual porosity around 5-10\% [12]. Young's modulus for TC20 had the highest value amongst these carbides, $476 \mathrm{GPa}$, due to the high stiffness of the matrix which can be as high as $560 \mathrm{GPa}$ $[1,23]$.

The fracture toughness of the composites can be considered equivalent from a statistical point of view, even if a slight decrease of the mean value with increasing $\mathrm{MoSi}_{2}$ content seems apparent from the data concerning HfC in Table 1. The values obtained are in the range of the values reported in the literature for such composites $\left(2.6-5.8 \mathrm{MPa} \cdot \mathrm{m}^{1 / 2}\right)[2$, $3,24,25]$, despite different compositions and densification techniques. No evidence of toughening mechanisms like crack deflection or crack pinning was observed in the crack paths generated by $10 \mathrm{~kg}$ indentations. A slightly higher value was recorded for TC20, probably due to the more marked metallic behavior of this compound. The tendency of TaCbased materials to exhibit a higher toughness compared to other carbides such as HfC was also found for hot pressed carbide-based materials containing either $\mathrm{MoSi}_{2}$ or $\mathrm{TaSi}_{2}$ [13].

The flexural strength tested at room temperature was around $270 \mathrm{MPa}$ for ZC20. As the fractographic analysis did not evidence any critical flaw, such as large inclusions or abnormal grains, it has to be concluded that the strength was mainly affected by the coarse microstructure, the presence of residual porosity, and the low fracture toughness. It must be pointed out that this value is in the range, or even higher, than those reported in the literature for other $\mathrm{ZrC}$-based materials (220-320 MPa) [24-26]. The room temperature flexural strength was similar for compositions HC5 and HC10, whilst composition HC20 showed a lower value (Table 2). Typical critical flaws observed after strength tests were large $\mathrm{MoSi}_{2}$ agglomerates, which had the tendency to form in the $\mathrm{MoSi}_{2}$ richer compositions, or large grains. Prismatic HfC grains of dimensions around $20 \mu \mathrm{m}$ were in fact observed to act as critical defects, as illustrated in Figure 9. The presence of such triangular grains was due to preferential growth along the 111 planes, which are the most densely populated and favored to grow at high temperature. Therefore, the factors inducing the strength decrease with increasing additive content could be basically the exaggerated grain growth of $\mathrm{HfC}$, the increasing of $\mathrm{MoSi}_{2}$ agglomerates size and the slight decrease of toughness. When the ultrasonication step was introduced during the preparation of HfC-based composites, the mean grain size decreased from 2.9 to $1.8 \mu \mathrm{m}$ and the microstructure was more uniform with no agglomerates or large grains. As a result, the flexural strength raised up to $538 \pm 22 \mathrm{MPa}$, compared to the former $452 \pm 90 \mathrm{MPa}$, and the standard deviation decreased significantly from 20 to $4 \%$. The new value obtained is even higher than that found for hot pressed HfC-based materials (417-464 MPa) [13].

The highest value of strength was obtained for the TC20 sample, $590 \mathrm{MPa}$, despite a mean grain size of about $7 \mu \mathrm{m}$. Similar hot pressed TaC-based ceramics containing silicides as sintering aids achieved values in the range $680-900 \mathrm{MPa}$ [13] when the matrix grains were kept between 1.5-2.5 $\mu \mathrm{m}$. This suggests that after optimization of powder treatment, such values could be potentially reached even by pressureless sintering. 


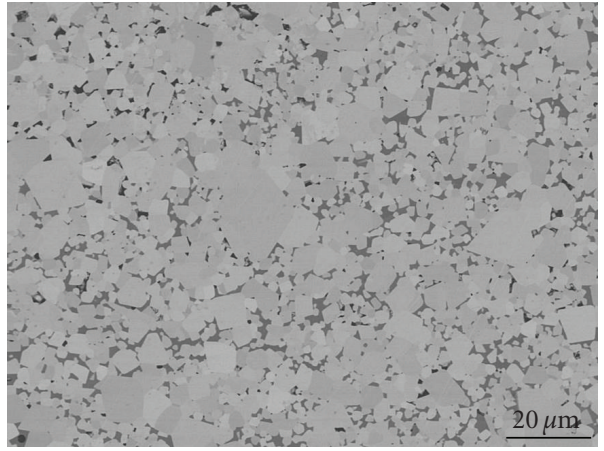

(a)

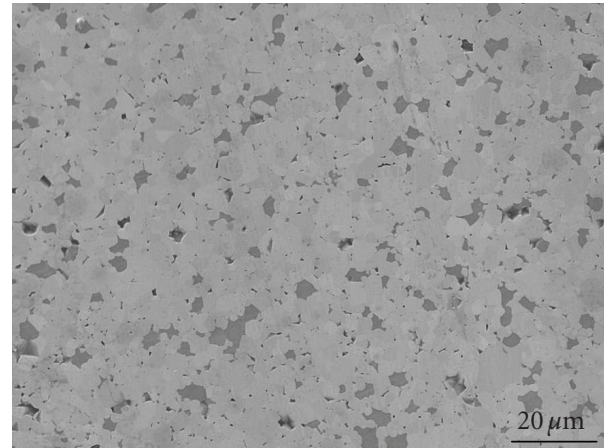

(b)

FIGURE 5: SEM micrographs of the polished surface of (a) HC10 and (b) HC10* (ultrasonicated). The bright grains are HfC, and the dark phase is $\mathrm{MoSi}_{2}$. Note the change in the matrix morphology and size after the ultrasonication step in (b).

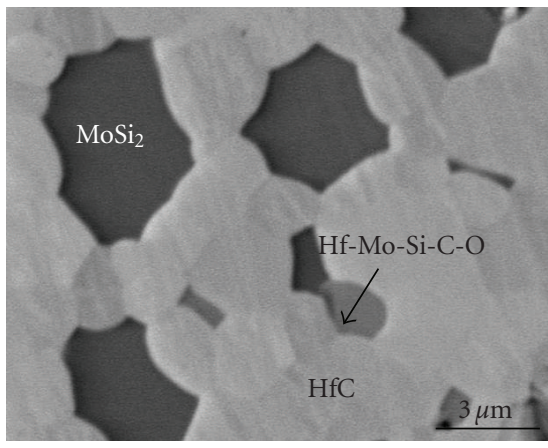

(a)

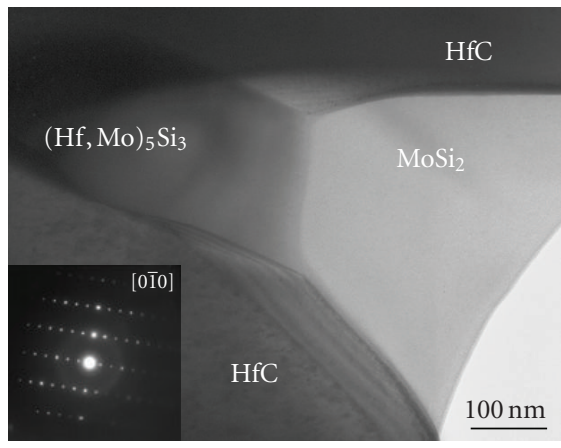

(b)

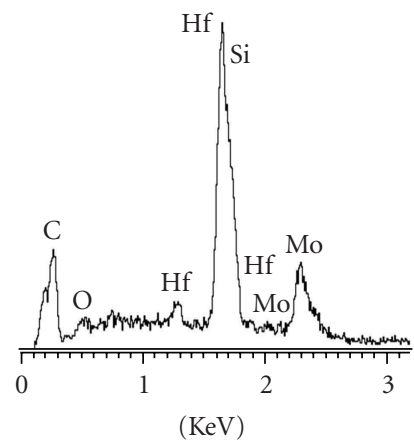

(c)

FIgure 6: (a) SEM micrographs of the polished surface of HC20. The bright grains are HfC, the dark phase is MoSi ${ }_{2}$, the arrow indicates the reaction product formed during sintering containing Hf-Mo-Si-C. (b) BF-TEM image evidencing the reaction product, identified as $(\mathrm{Hf}, \mathrm{Mo})_{5} \mathrm{Si}_{3}$ and the corresponding electron diffraction pattern and (c) the EDS spectrum.

Given the poor oxidation resistance of carbides $[3,4,11$, $12,27]$, high-temperature bending test was conducted in a chamber flushed with Argon in order to avoid contact of the samples with oxygen. Despite the protective environment, for ZC20 the flexural strength values at $1200^{\circ} \mathrm{C}$ decreased to about $43 \%$ of the room temperature value and the samples were covered by a whitish layer implying that they reacted with residual oxygen present in the test chamber. At $1500^{\circ} \mathrm{C}$, despite the Ar flux, the bars were broken apart by a catastrophic oxidation before the execution of the bending tests.

For all the HfC-based samples there was a decrease in strength both at $1200^{\circ} \mathrm{C}$ and at $1500^{\circ} \mathrm{C}$, a decrease that was more pronounced for HC5 composite. Examples of broken specimens after high-temperature flexural strength are reported in Figure 10. It can be noticed that for the sample HC5, in Figure 10(a), cracking at the corners of the bars occurred. It is probable that the external Hf-O-C layer was well adhered to the unreacted bulk and did not allow stress relaxation, leading to the opening of the cube edges and formation of the Maltese cross. This phenomenon was also previously reported for the oxidation of other HfC-based ceramics and TaC-based materials [13,27]. The Maltese cross was less pronounced in HC20, in Figure 10(b), because of the presence of $\mathrm{SiO}_{2}$-glassy phase that favoured the stress relaxation associated to the phase transformation from $\mathrm{HfC}$ to $\mathrm{HfO}_{2}$. The fractured surface of the oxidized samples testified the presence of a sealing glassy phase in HC20, which provides a smooth and gluey appearance compared to the rough aspect of HC5 (insets in Figure 10).

3.4. Comparison among $\mathrm{ZrC}, \mathrm{HfC}$, and TaC Composites. A definitive characterization of the transition metal carbides is difficult, since the thermodynamics, the physical and mechanical properties are sensitive to a number of factors which tend to vary widely among samples. These factors consist of the crystal structure and lattice parameters, including the presence of vacancy ordering; the chemical composition, including not only the overall carbon-to-metal ratio present in the bulk sample, but also the amount of free carbon versus combined carbon; the impurities concentration, particularly that of oxygen; the overall defect structure, including grain size, dislocations, and porosity; and the sample homogeneity.

The transition metal carbides show a range of nonstoichiometries and possibilities for vacancy ordering that have a great effect on the thermophysical and mechanical properties of the metal carbides; however, the details of these effects are 


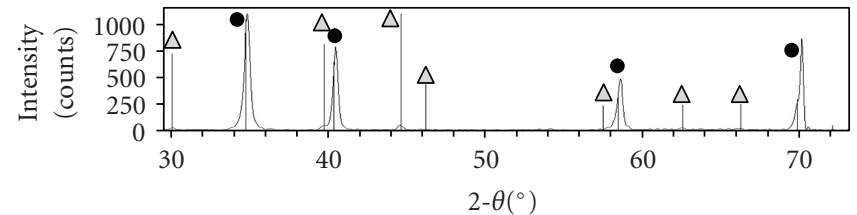

- $\mathrm{TaC} \# 65-0282$

$\triangle \mathrm{MoSi}_{2} \# 65-2645$

(a)

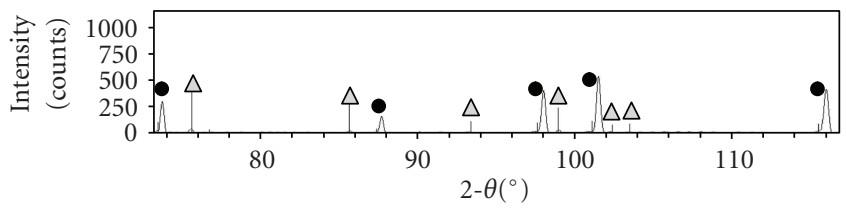

- $\mathrm{TaC} \# 65-0282$

$\triangle \mathrm{MoSi}_{2} \# 65-2645$

(b)

Figure 7: X-ray diffraction pattern of TC20. Superimposed PDF lines corresponding to $\mathrm{TaC}$ and $\mathrm{MoSi}_{2}$; note the peaks shift of the TaC phase in the composite.

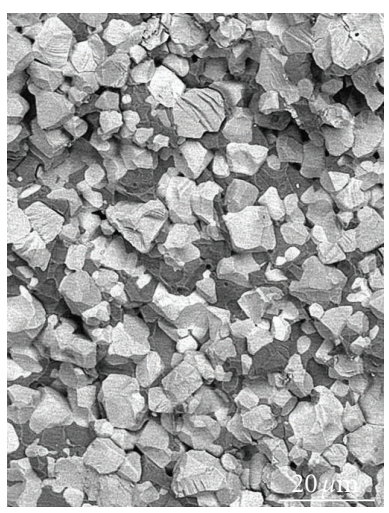

(a)

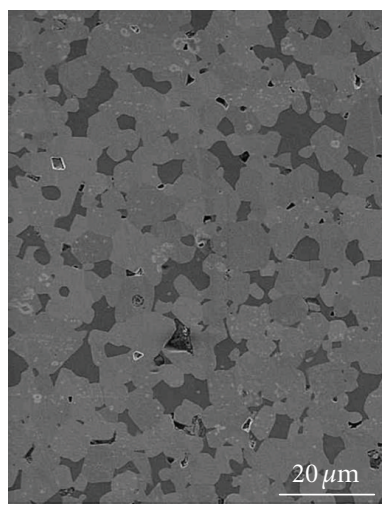

(b)

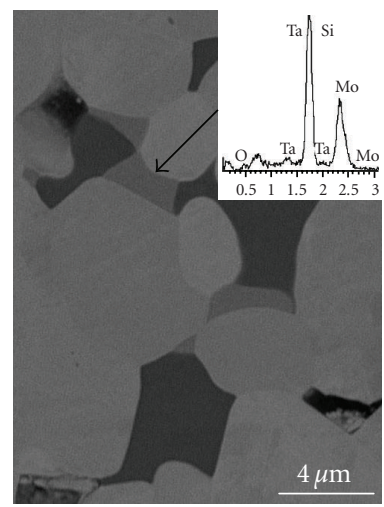

(c)

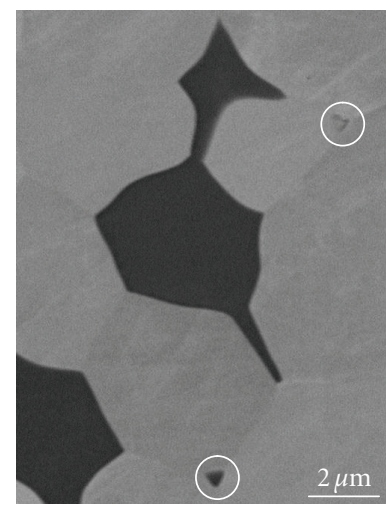

(d)

FIGURE 8: (a) Fractured and (b)-(d) polished section of TC20. The bright phase is TaC, the dark phase is $\mathrm{MoSi}_{2}$, and the arrow in (c) indicates the reaction product formed during sintering, identified as $(\mathrm{Ta}, \mathrm{Mo})_{5} \mathrm{Si}_{3}$. (d) $\mathrm{MoSi}_{2}$ phase squeezed among the matrix and, circled, the triple point junctions constituted by $(\mathrm{Ta}, \mathrm{Mo})_{5} \mathrm{Si}_{2} \mathrm{C}$.

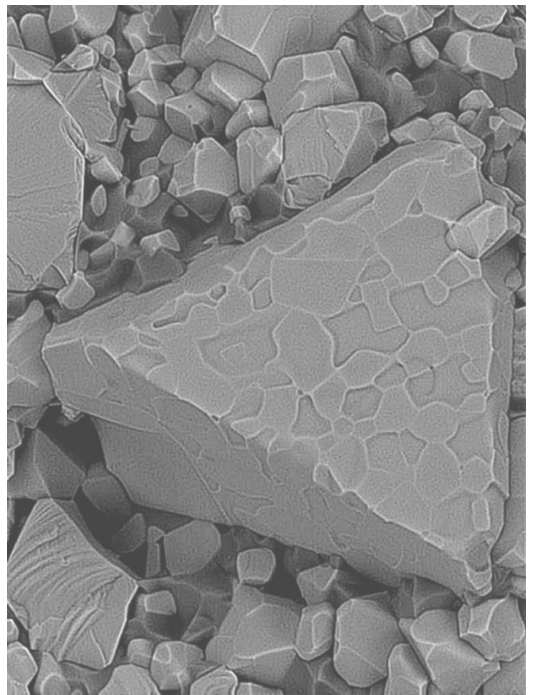

(a)

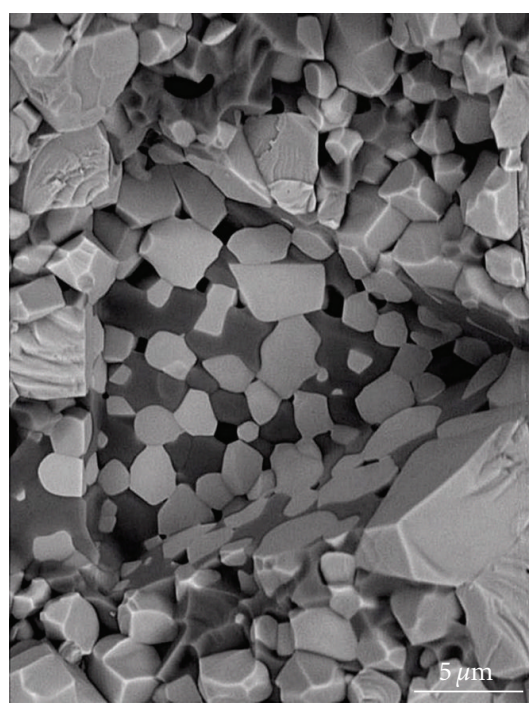

(b)

FIGURE 9: Fracture surface of HC10 after bending test at room temperature: abnormal grain which acted as critical defect, both the two surfaces of the bars are shown. After improving of the powder treatment, the flexural strength increased of about $100 \mathrm{MPa}$ and decreased the standard deviation. 


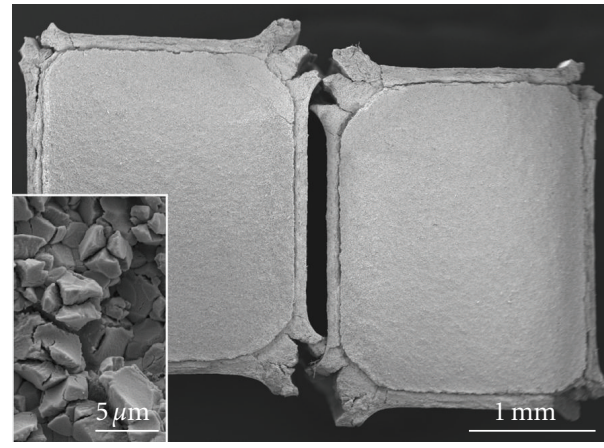

(a)

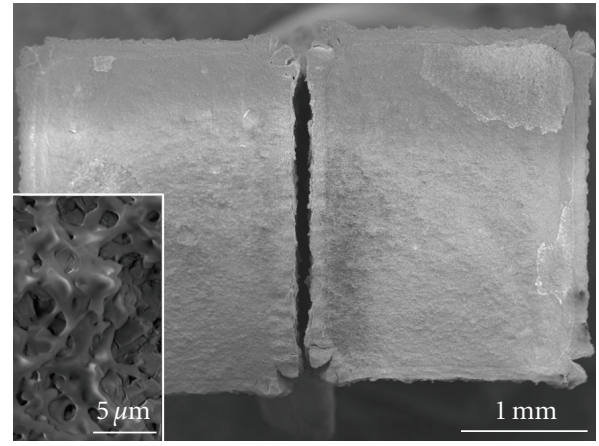

(b)

Figure 10: Fracture analysis after bending tests of $\mathrm{HfC}$-based composites at $1500^{\circ} \mathrm{C}$ in Ar. Appearance of the bars and, in the insets, fracture surface of (a) HC5 and (b) HC20.

still a matter of debate in the literature, due to the difficulties inherent in synthesizing pure compounds and in measuring the exact features of the crystal structure of a given sample.

In this paragraph, we try to catch some analogies and differences among the three systems just presented.

3.4.1. Grain Coarsening. The transition metals $\mathrm{M}$ in groups III-VI can form non-stoichiometric carbides MC, with the $\mathrm{NaCl}$ structure within the range $0.5<x<1$ with a disordered distribution of carbon atoms at high temperatures [3]. With the increment of the amount of carbon atoms that fill the octahedral free sites, a gradual change of the nature of the chemical bond takes place. This goes from predominantly metallic to the mixed metallic-covalent bond [23]. The order of stability of the carbides resulting from the bonds energy is $\mathrm{TaC}>\mathrm{HfC}>\mathrm{ZrC}$, which can however vary as a function of the number of vacancies.

The lattice energy and the stability of the compounds can be related to the microstructural features. During sintering, all the matrices underwent grains coarsening, which is indeed typical of cubic systems having many favorable planes of crystal growth. However only the HfC-based materials showed abnormal grain growth on the 111 planes, which is evidenced by the triangular prisms observed in the microstructure obtained with the conventional powder treatment (Figure 5(a)). This direction of growth is indeed the more energetically favorable, as it is the most densely populated. This different behavior could indicate that $\mathrm{ZrC}$ and $\mathrm{TaC}$ have the same grain grow rate on all the lattice planes, whilst HfC, more stable, has the preferential 111 family which grows at a very high rate suppressing the other families of planes. From the experimental evidence, the preferential grain growth on $\mathrm{HfC}$ can be inhibited by ultrasonication of the powder.

3.4.2. Influence of the Starting Powder. Another interesting difference among the three matrices is the presence of $\mathrm{SiC}$ and $\mathrm{SiO}_{2}$ species in the final microstructure. $\mathrm{ZrC}$-based composites contain a high amount of $\mathrm{SiC}$ and only traces of silica, and $\mathrm{TaC}$ contains a notable amount of $\mathrm{SiO}_{2}$ pockets and some $\mathrm{SiC}$. HfC was generally free of both $\mathrm{SiC}$ and silica.
These differences are related to the characteristics of the raw powders, especially in terms of $\mathrm{C}$ and $\mathrm{O}$ impurities.

Actually, $\mathrm{ZrC}$ powder contains a discrete amount of free C, $1.5 \mathrm{wt} \%$ (see Table 2). Free Carbon reduces $\mathrm{MoSi}_{2}$, according to reaction (1), and $\mathrm{SiO}_{2}$ species, according to reaction (2):

$$
\begin{gathered}
5 \mathrm{MoSi}_{2}+7 \mathrm{C}=\mathrm{Mo}_{5} \mathrm{Si}_{3}+7 \mathrm{SiC} \\
\mathrm{SiO}_{2}+2 \mathrm{C}=\mathrm{SiC}+\mathrm{CO}_{2} .
\end{gathered}
$$

Before reaction 2 is fully completed, silica-based liquid is extracted by capillary forces to the edge, where a C-richer environment allows the complete carburization to $\mathrm{SiC}$. This is confirmed by the abundancy of $\mathrm{SiC}$ phase in external part of the sintered pellets (Figure 3(b)).

In TaC-based materials, a notable concentration of residual $\mathrm{SiO}_{\mathrm{x}}$-based phases was found. This indicates that, compared to $\mathrm{HfC}, \mathrm{TaC}$ powder mixture has a higher content of oxygen contamination. This has at least two consequences: firstly, a higher amount of sintering aid has to be used to obtain a good densification ( $>10$ vol\% against $5 \mathrm{vol} \%$ for HfC); secondly the elimination of residual silica requires longer times. Hence, if the closure of the pores during densification occurs before the complete carburization of $\mathrm{SiO} / \mathrm{SiO}_{2}$ species, silica pockets are retained in the microstructure.

3.4.3. Sintering Mechanism. It is well known that raw carbide powder particles are always contaminated by oxygen present as metal oxide. The inhibition of sintering in nonoxide ceramics such as carbides is generally attributed to the presence of these oxide impurities. It can be stated that the sintering mechanism is common to the three materials, but with some little differences.

As previously reported [28], $\mathrm{MoSi}_{2}$ addition is effective to improve the densification as it promotes the removal of surface oxides through an oxidation reaction:

$$
\mathrm{MoSi}_{2}+7 \mathrm{O}_{2}=\mathrm{Mo}_{5} \mathrm{Si}_{3}+7 \mathrm{SiO}_{2} .
$$

$\mathrm{Mo}_{5} \mathrm{Si}_{3}$ from reaction 3 is likely to be the starting phase for the formation of liquid $\mathrm{Zr}-\mathrm{Si}$ or Hf-Si species that favour matter transfer mechanisms. 
Concerning $\mathrm{ZrC}$, $\mathrm{Zr}$ completely substitutes $\mathrm{Mo}$ in $\mathrm{Mo}_{5} \mathrm{Si}_{3}$ and forms $\mathrm{Zr}_{5} \mathrm{Si}_{3}$, which in turn is locally transformed into $\mathrm{Zr}_{2} \mathrm{Si}$ (if next to $\mathrm{C}$ sources) or $\mathrm{ZrSi}$ and $\mathrm{ZrSi}_{2}$ (if next to $\mathrm{Si}$ sources). Therefore, neither $\mathrm{Mo}_{5} \mathrm{Si}_{3}$ nor $\mathrm{Zr}_{5} \mathrm{Si}_{3}$ was found in the final microstructure. Concerning $\mathrm{TaC}$, the $(\mathrm{M}, \mathrm{Mo})_{5} \mathrm{Si}_{3}$ was more abundant than in HfC. For HfC, Hf has a lower mobility than $\mathrm{Zr}$ and only partially substitutes Mo sites in the $\mathrm{Mo}_{5} \mathrm{Si}_{3}$ structure and hence little amounts of ( $\mathrm{Hf}$, $\mathrm{Mo})_{5} \mathrm{Si}_{3}$ were observed in the final microstructure. From the microstructural analysis of the present materials, that is, in terms of amount and size of the $\mathrm{M}_{5} \mathrm{Si}_{3}$ phase, we can assert that $\mathrm{HfC}$ is the most stable of the three matrices, $\mathrm{TaC}$ has a reactivity in-between $\mathrm{ZrC}$ and $\mathrm{HfC}$, and $\mathrm{ZrC}$ is least stable.

After all, $\mathrm{HfC}$ is the powder more prone to densification, a feature which can be related to a lower degree of oxygen contamination in the starting powder and to a lower tendency for oxygen take-up during powder processing. The absence of silica or $\mathrm{SiC}$ phases indicates that silica deriving from reaction 3 , if formed, is eliminated before pore closure by carbothermal reduction.

3.4.4. Formation of Solid Solutions. It was previously stated that the transition metal carbides generally have carbon vacancies, due to the high mobility of carbon from the MC lattice [29]. We can deduce that the higher number of vacancies is, the more the cell is slack and hence prone to host external atoms, like Mo. In $\mathrm{ZrC}$ a peaks shift by $\mathrm{x}$-ray diffraction was observed and about 4 at $\%$ of Mo was detected by SEM-EDS in the matrix grains [28]; less than 2 at $\%$ of Mo was detected by EDS in TaC-composites accompanied with peaks shift in the x-ray spectrum; on the contrary, HfCcomposites did not display neither peaks shift nor Mo edge by EDS. From these analyses we can presume that $\mathrm{ZrC}$ has the highest number of vacancies in the lattice and is the matrix which forms solid solutions more easily. $\mathrm{ZrC}$ is followed by $\mathrm{TaC}$ and finally by $\mathrm{HfC}$, which is the most stable.

3.4.5. Mechanical Properties. The mechanical properties are a result of the microstructural features, intrinsic properties, and defective structure of the material. Only the composites containing $20 \mathrm{vol} \%$ of $\mathrm{MoSi}_{2}$ will be considered for comparison.

Once again, the starting powder resulted of paramount importance for the obtainment of a fine and dense microstructure and hence for high mechanical properties. Under this perspective, ZC20 displayed the lowest mechanical properties due to the coarse microstructure and around $5 \%$ of residual porosity. What is also evident from the mechanical properties in Table 2, is that $\mathrm{TaC}$ possesses superior intrinsic properties, as far as stiffness and room temperature strength is concerned, reflecting its strong bonds.

As to the high-temperature behavior, the best performing material is the one possessing the highly stable oxide, that is, $\mathrm{HfO}_{2}$, followed by $\mathrm{ZrO}_{2}$ and $\mathrm{Ta}_{2} \mathrm{O}_{5}$. The better performance of $\mathrm{HfC}$ at high temperature is supposed to be related also to the presence of an interlayer constituted by oxycarbides, which exhibit higher oxidation resistance than the external pure $\mathrm{HfO}_{2}$ which forms on the surface. However, the presence of a high content of $\mathrm{MoSi}_{2}$, which enables the development of a protective silica layer on the surface, has not to be neglected, too. Keeping in mind the reactivity of the three matrices with $\mathrm{MoSi}_{2}$, we expect a nearly unaltered content in HfC, lower amount in $\mathrm{TaC}$, and much less in $\mathrm{ZrC}$. The low strength of ZC20 at high temperature (156 $\mathrm{MPa}$ ) could be also due to a content of $\mathrm{MoSi}_{2}$ lower than the nominal composition.

\section{Conclusions}

Carbides of zirconium, hafnium, and tantalum were consolidated by pressureless sintering with the addition of molybdenum silicide. $5 \mathrm{vol} \%$ was enough to achieve the full density in $\mathrm{HfC}$ at $1950^{\circ} \mathrm{C}, \mathrm{TaC}$ required at least $10 \mathrm{vol} \%$, whilst $\mathrm{ZrC} 20 \mathrm{vol} \%$. For this last composition, the reaction between matrix and sintering additive with formation of $\mathrm{SiC}$ was crucial. For all the three groups of ceramics, reaction products, based on $(\mathrm{M}, \mathrm{Mo})_{5} \mathrm{Si}_{3}$ with carbon and oxygen traces, were observed as interfacial phase between the matrix and $\mathrm{MoSi}_{2}$ or at the triple points, confirming that these systems are highly reactive in reducing environment. The mean grain size was generally coarse, $3-7 \mu \mathrm{m}$, indicating a coarsening tendency of the carbide matrices. Abnormal grain growth in $\mathrm{HfC}$ was suppressed introducing an ultrasonication step in the powder treatment. The microstructure improvement for the selected composition led to an increase of the room temperature flexural strength of $100 \mathrm{MPa}$ and to a lower standard deviation.

The highest room temperature properties were those displayed by the TaC-based composite (strength $590 \mathrm{MPa}$, Young's modulus $480 \mathrm{GPa}$ ). High-temperature tests has to be carried out in protective environment, because even $20 \mathrm{vol} \%$ of $\mathrm{MoSi}_{2}$ is not effective in suppressing the pest oxidation of the carbides. The maximum high-temperature strength was for HfC-based composites, $300 \mathrm{MPa}$ at $1500^{\circ} \mathrm{C}$.

The purity of the starting powder was confirmed to play an essential role in the reactivity, sintering behavior, and microstructure evolution of the carbides. HfC was confirmed to be the most stable phase, followed by $\mathrm{TaC}$ and $\mathrm{ZrC}$.

\section{Acknowledgment}

The authors wish to thank G. Celotti for X-ray diffraction and C. Melandri for mechanical testing.

\section{References}

[1] H. O. Pierson, Handbook of Refractory Carbides and Nitrides, William Andrew Publishing, Norwich, NY, USA, 2001.

[2] L. E. Toth, "Transition metal carbides and nitrides," in Refractory Materials, A Series of Monographs, J. L. Margrave, Ed., pp. 6-10, Academic Press, New York, NY, USA, 1971.

[3] E. K. Storms, "The Refractory carbides," in Refractory Materials, A Series of Monographs, J. L. Margrave, Ed., p. 94, Academic Press, New York, NY, USA, 1967.

[4] E. L. Courtright, J. T. Prater, G. R. Holcomb, G. R. ST. Pierre, and R. A. Rapp, "Oxidation of hafnium carbide and hafnium 
carbide with additions of tantalum and praseodymium," Oxidation of Metals, vol. 36, no. 5-6, pp. 423-437, 1991.

[5] A. Sayir, "Carbon fiber reinforced hafnium carbide composite," Journal of Materials Science, vol. 39, no. 19, pp. 5995-6003, 2004.

[6] S. A. Shvab and F. F. Egorov, "Structure and some properties of sintered tantalum carbide," Soviet Powder Metallurgy and Metal Ceramics, vol. 21, no. 11, pp. 894-897, 1982.

[7] G. V. Samonov and R. Y. Petrikina, "Sintering of metals, carbides, and oxides by hot pressing," Physics of Sintering, vol. 2, no. 3, pp. 1-20, 1970.

[8] J. S. Jackson, "Hot pressing high-temperature compounds," Powder Metallurgy, vol. 8, p. 73, 1961.

[9] L. Ramqvist, "Hot pressing of metallic carbides," Powder Metallurgy, vol. 9, no. 17, pp. 26-46, 1966.

[10] X. Zhang, G. E. Hilmas, W. G. Fahrenholtz, and D. M. Deason, "Hot pressing of tantalum carbide with and without sintering additives," Journal of the American Ceramic Society, vol. 90, no. 2, pp. 393-401, 2007.

[11] M. M. Opeka, I. G. Talmy, E. J. Wuchina, J. A. Zaykoski, and S. J. Causey, "Mechanical, thermal, and oxidation properties of refractory hafnium and zirconium compounds," Journal of the European Ceramic Society, vol. 19, no. 13-14, pp. 2405-2414, 1999.

[12] E. Wuchina, M. Opeka, S. Causey et al., "Designing for ultrahigh-temperature applications: the mechanical and thermal properties of $\mathrm{HfB}_{2}, \mathrm{HfC}_{x}, \mathrm{HfN}_{x}$ and $\alpha \mathrm{Hf}(\mathrm{N})$," Journal of Materials Science, vol. 39, no. 19, pp. 5939-5949, 2004.

[13] D. Sciti, L. Silvestroni, S. Guicciardi, D. D. Fabbriche, and A. Bellosi, "Processing, mechanical properties and oxidation behaviour of $\mathrm{TaC}$ and $\mathrm{HfC}$ composites containing 15 vol\% $\mathrm{TaSi}_{2}$ or $\mathrm{MoSi}_{2}$," Journal of Materials Research, vol. 24, no. 6, pp. 2056-2065, 2009.

[14] D. Sciti, S. Guicciardi, and M. Nygren, "Spark plasma sintering and mechanical behaviour of ZrC-based composites," Scripta Materialia, vol. 59, no. 6, pp. 638-641, 2008.

[15] D. Sciti, S. Guicciardi, and M. Nygren, "Densification and mechanical behavior of $\mathrm{HfC}$ and $\mathrm{HfB}_{2}$ fabricated by spark plasma sintering," Journal of the American Ceramic Society, vol. 91, no. 5, pp. 1433-1440, 2008.

[16] L. Silvestroni and D. Sciti, "Effects of MoSi $i_{2}$ additions on the properties of $\mathrm{Hf}$ - and $\mathrm{Zr}-\mathrm{B}_{2}$ composites produced by pressureless sintering," Scripta Materialia, vol. 57, no. 2, pp. 165-168, 2007.

[17] D. G. Munz, J. L. Shannon Jr., and R. T. Bubsey, "Fracture toughness calculation from maximum load in four point bend tests of chevron notch specimens," International Journal of Fracture, vol. 16, no. 3, pp. R137-R141, 1980.

[18] R. V. Sara, “The system zirconium-carbon," Journal of the American Ceramic Society, vol. 48, no. 5, pp. 243-247, 1965.

[19] G. Santoro, "Variation of some properties of Tantalum carbide with carbon content," Transactions of The Metallurgical Society of AIME, vol. 227, pp. 1361-1368, 1963.

[20] D. J. Rowcliffe and W. J. Warren, "Structure and properties of tantalum carbide crystals," Journal of Materials Science, vol. 5, no. 4, pp. 345-350, 1970.

[21] H. E. Exner, "Physical and chemical nature of cemented carbides," International metals reviews, vol. 24, no. 4, pp. 149173, 1979.

[22] A. Newman, T. Jewett, S. Sampath, C. Berndt, and H. Herman, "Indentation response of molybdenum disilicide," Journal of Materials Research, vol. 13, no. 9, pp. 2662-2671, 1998.

[23] A. Krajewski, L. D'Alessio, and G. De Maria, "Physisochemical and thermophysical properties of cubic binary carbides," Crystal Research and Technology, vol. 33, no. 3, pp. 341-374, 1997.

[24] E. Min-Haga and W. D. Scott, "Sintering and mechanical properties of $\mathrm{ZrC}^{-\mathrm{ZrO}_{2}}$ composites," Journal of Materials Science, vol. 23, no. 8, pp. 2865-2870, 1988.

[25] T. Tsuchida and S. Yamamoto, "MA-SHS and SPS of $\mathrm{ZrB}_{2}-\mathrm{ZrC}$ composites," Solid State Ionics, vol. 172, no. 1-4, pp. 215-216, 2004.

[26] K. H. Kim and K. B. Shim, "The effect of lanthanum on the fabrication of $\mathrm{ZrB}_{2}-\mathrm{ZrC}$ composites by spark plasma sintering," Materials Characterization, vol. 50, no. 1, pp. 3137, 2003.

[27] M. Desmaison-Brut, N. Alexandre, and J. Desmaison, "Comparison of the oxidation behaviour of two dense hot isostatically pressed tantalum carbide ( $\mathrm{TaC}$ and $\left.\mathrm{Ta}_{2} \mathrm{C}\right)$ materials," Journal of the European Ceramic Society, vol. 17, no. 11, pp. 1325-1334, 1997.

[28] L. Silvestroni, D. Sciti, J. Kling, S. Lauterbach, and H.-J. Kleebe, "Sintering mechanisms of zirconium and hafnium carbides doped with $\mathrm{MoSi}_{2}$," Journal of the American Ceramic Society, vol. 92, no. 7, pp. 1574-1579, 2009.

[29] F. J. J. Van Loo, W. Wakelkamp, G. F. Bastin, and R. Metselaar, "Diffusion of carbon in $\mathrm{TiC}_{1-y}$ and $\mathrm{ZrCC}_{1-y}$," Solid State Ionics, vol. 32-33, no. 2, pp. 824-832, 1989. 

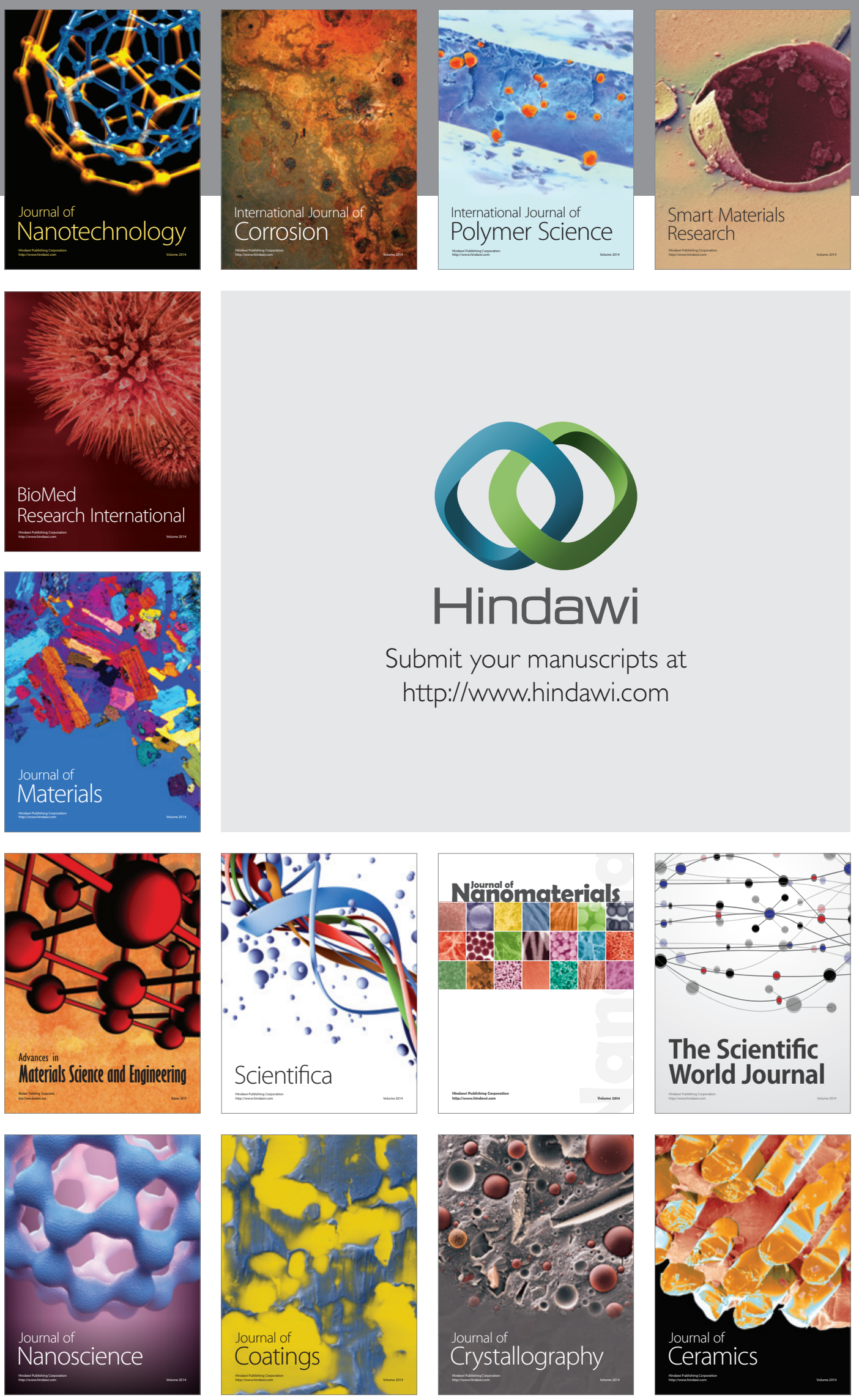

The Scientific World Journal

Submit your manuscripts at

http://www.hindawi.com

\section{World Journal}

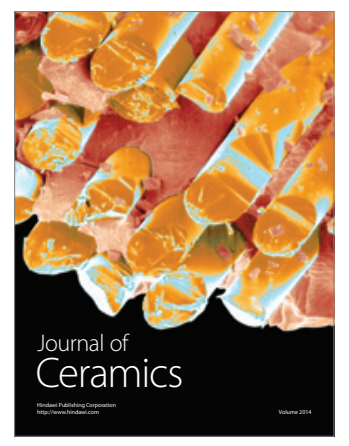

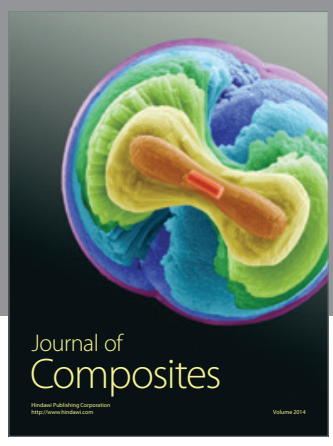
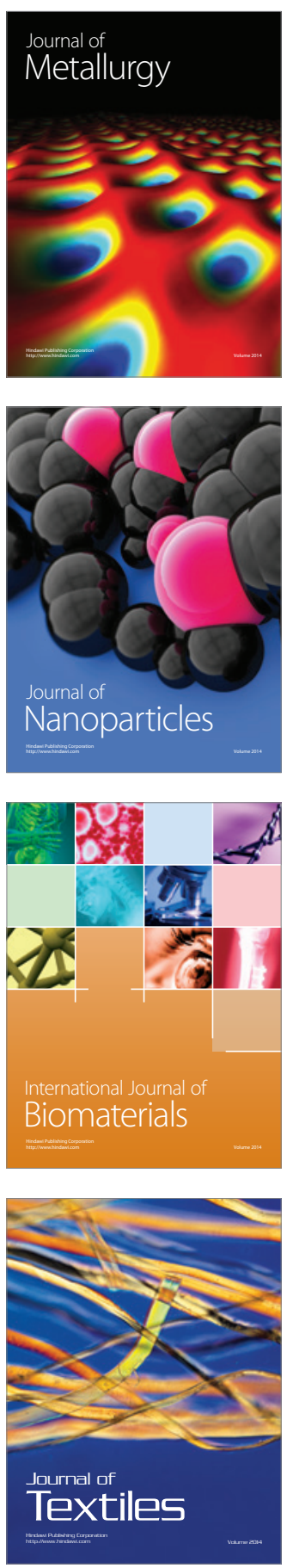